EXEMPLARIa Classica

Journal of Classical Philology

19, 2015, pp. 149-153

ISSN 1699-3225

\title{
EL LIBRO X DE LAS MET. DE OVIDIO: A PROPÓSITO DE UN RECIENTE COMENTARIO
}

Lee Fratantuono, Ovid. Metamorphoses X, London: Bloomsbury, 2014, x + 276 pp., ISBN 978-14-7252-290-0. ${ }^{1}$

Autor ya de un comentario al libro XI de la Eneida y de un ensayo sobre la estructura de las Metamorfosis de Ovidio², Lee Fratantuono ha publicado un comentario al libro X de las Metamorfosis dirigido a los "undergraduates and sixth formers". Por esta razón, Fratantuono dice haberse centrado sobre todo en aquellos aspectos que, en su opinión, podían plantear dificultades a los lectores noveles de Ovidio (p. vii), aunque sin renunciar a aportar información que pueda resultar útil para lectores más avanzados o incluso para los especialistas.

Lo más interesante del trabajo de Fratantuono son los pasajes en que se examinan los lazos estructurales y temáticos que unen los distintos episodios del libro décimo entre sí y con otros libros de las Metamorfosis, así como los lugares en que se tratan los contactos intertextuales con otros autores latinos y Virgilio en particular. Sin embargo, en buena medida, el libro no parece haber sido fruto de un lento y madurado proceso de reflexión sobre el texto. Con demasiada frecuencia, las buenas ideas que aparecen esbozadas en un determinado lugar quedan sepultadas entre la sobreabundancia de comentarios triviales que no contribuyen a iluminar y esclarecer el texto.

\footnotetext{
${ }^{1}$ Este artículo reseña es un resultado indirecto de mi tesis doctoral en curso "Edición crítica y comentario textual del libro X de las Metamorfosis de Ovidio", realizada en el seno del grupo de investigación Nicolaus Heinsius (HUM-261) bajo la dirección de los Prof. Antonio Ramírez de Verger y José Luis Vidal, gracias a una beca FPU del Ministerio de Educación. Por otro lado, este artículo-reseña se inserta en el proyecto de investigación FFI2013-41056-P. Todas las discusiones textuales que aparecen a continuación son versiones resumidas y adaptadas del comentario crítico de mi tesis doctoral en curso. Debo agradecer a los Prof. Antonio Ramírez de Verger, Juan A. Estévez Sola y Salvador Oliva las justas sugerencias que me han hecho a partir de la lectura de un borrador de estas páginas.

${ }^{2}$ L. Fratantuono, A Commentary on Virgil, Aeneid XI, Bruxelles, 2009; Madness Transformed: a Reading of Ovid's Metamorphoses, Lanham, 2011. Con posterioridad al libro reseñado aquí, Fratantuono ha publicado en la editorial Brill un comentario al libro 5 de la Eneida junto a R. Alden Smith (Virgil, Aeneid 5: text, translation and commentary, Leiden, 2015), que todavía no conozco.
} 


\section{LA INTRODUCCIÓN}

La introducción está dedicada fundamentalmente a contextualizar el libro décimo en su lugar dentro del conjunto de la obra y a delinear los lazos estructurales o temáticos que unen y relacionan los distintos episodios entre sí y con el resto de la obra. La introducción sigue, pues, la senda de otros estudiosos que se han fijado en la estructura del carmen perpetuum y es una continuación del trabajo del propio Fratantuono en esa dirección ${ }^{3}$. Los lazos de intertextualidad entre Ovidio y otros autores, señaladamente Lucrecio y Virgilio, son otro notable foco de interés de la introducción.

En ese sentido, resultan particularmente atractivos los paralelismos señalados entre la canción de Orfeo en el libro décimo y la de Calíope en el libro quinto (que cierran, respectivamente, la primera y segunda péntada). Resulta también muy sugerente la comparación entre Atalanta y Camila, su modelo parcial (compárese, por ejemplo, 10.654-5 con Verg. Aen. 7.807-114).

De todas formas, se habría agradecido una explicación detallada sobre las razones, fundadas, que permiten dividir en tres grandes partes una obra de la extensión de las Metamorfosis (Fratantuono traza tan sólo analogías, que me parecen débiles, con la estructura tripartita de la Eneida o con los tres libros de Amores, entre otros). A este respecto, el artículo de Holzberg ${ }^{5}$, mencionado por Fratantuono, sigue pareciéndome un óptimo punto de partida. Seguramente, también habría sido procedente un análisis más pausado y ordenado de la estructura interna del libro décimo. Además, teniendo en cuenta el público para el que está pensado el libro (y el tipo de notas que luego aparecen en el comentario), no habría sido inútil ofrecer algunos datos elementales sobre la obra y el autor y presentar algunas claves de lectura de la obra.

Por otra parte, Fratantuono también destina parte de la introducción a explorar algunos de los temas que, a su decir, centran el interés del poeta a lo largo del libro décimo. En particular, Fratantuono afirma que el libro propone mucho material de reflexión sobre cuestiones etnográficas, filosóficas y políticas. No obstante, me parece dudoso que la preocupación de Ovidio por ese tipo de asuntos se manifieste en el libro que nos ocupa de forma clara y como un elemento central ${ }^{6}$. Así, la simple presencia de Orfeo y de Proserpina

${ }^{3}$ Fratantuono, Madness. A contrastar con la reseña de I. Ziogas, BMCRev, 2012-04-09 (http://bmcr.brynmawr.edu/2012/2012-04-09.html).

${ }^{4}$ Fratantuono en su comentario al v. 654 sólo remite a los vv. 808-9. En realidad, el v. 654 emula Verg. Aen. 7.810-1, mientras que el v. 655 recoge Verg. Aen. 7.808-9. A su vez, Virgilio toma como modelo Hes. Frg. 62 Merkelbach-West. Recuérdese que Hes. Frg. 72-6 M-W contiene la historia de Atalanta, que es también modelo de Ovidio. Léase I. Ziogas, "Ovid as a Hesiodic Poet: Atalanta in the Catalogue of Women (fr. 72-6 M-W) and the Metamorphoses (10.560-707)", Mnemosyne 64, 2011, 249-70.

${ }^{5}$ N. Holzberg, "Ter Quinque Volumina as Carmen Perpetuum: The Division Into Books in Ovid's Metamorfoses”, MD 40, 1998, 77-98; sobre el libro décimo, esp. 85-6.

${ }^{6}$ Como es lógico, hay voluntad de ofrecer etiologías, pero no se trata en absoluto de un tema esencial ni exclusivo del libro décimo. 
en el libro, con la catábasis de Orfeo, no es una razón suficiente como para suponer que Ovidio esté evocando doctrinas filosóficas y escatológicas. De la misma forma, tampoco creo que la participación de Apolo en dos de las historias narradas pueda entenderse como una crítica a Augusto o que la mera aparición del término bulla encierre una reflexión sobre los aristócratas romanos o la Roma contemporánea. En realidad, Fratantuono no tiene muchos escrúpulos para trazar todo tipo de paralelismos, analogías o hipótesis más o menos vagas, agarrándose, muchas veces, a una sola palabra o expresión sacada de su contexto, y a pesar de que falten argumentos convincentes y ejemplos concretos de los textos para demostrar que su idea va más allá de la mera coincidencia o de la especulación gratuita. Veremos algunos ejemplos más sobre la cuestión en las páginas 220-1.

En mi opinión, y como en realidad admite el propio Fratantuono, el libro décimo de las Metamorfosis es, por encima de todo lo demás, una prueba fehaciente del formidable talento e ingenio como narrador del poeta de Sulmona.

\section{EL TEXTO}

Después del prefacio y de la introducción, el volumen reproduce, sin aparato crítico, el texto oxoniense de R. J. Tarrant $(2004)^{7}$. A continuación, me detendré un poco en la discusión del único cambio del texto que propone Fratantuono, así como en su discusión crítica de algunos otros pasajes.

\section{Discrepancia respecto a Tarrant}

Fratantuono se distancia de su edición de referencia tan sólo en el v. 733. Reproduzco a continuación el texto de Tarrant con su aparato $(2004,311)$, para una más cómoda discusión del pasaje:

sic fata [sc. Venus] cruorem [Adonidis]

nectare odorato sparsit, qui tactus ab illo

intumuit sic, ut fulvo perlucida caeno

surgere bulla solet;

733 fulvo] pluvio $F^{3 c} \varphi$ caeno Merkel : c(a)elo $\Omega$

La conjetura de $\mathrm{Merkel}^{8}$, aceptada por casi todos los editores posteriores, da lugar a un texto que no es en absoluto convincente, sobre todo porque el

${ }^{7}$ No hay duda de que la elección del texto es, a día de hoy, la mejor posible. Por otra parte, para evitar enojosas referencias cada vez que se repite un mismo título a lo largo de estas páginas, he optado, con el permiso de los editores de la revista, por poner las referencias de esas obras en un listado final de más fácil consulta.

${ }^{8}$ En P. Ovidii Nasonis Metamorphoses. Auswahl für Schulen. Mit erläuternden Anmerkungen und einem mythologischgeographischen Register versehen von Dr. Johannes Siebelis. Zweites Heft Buch X-XV und das mythologisch-geographischen Register enthaltend. Zwölfte Auflage. Besorgt von Dr. Friedrich Polle. Leipzig, 1888, 12; 152. 
barro o el cieno en proceso de fermentación no parecen un símil adecuado a la belleza de Adonis y a la fragilidad de la anémona. Además no está claro cómo de ese cieno amarillento en fermentación podrían surgir burbujas perlucidae. Asimismo, el paralelo de 1.418-9 (caenumque udaeque paludes / intumuere aestu), aducido por Reed $(2013,301)$, no me parece completamente equiparable, puesto que allí se habla de la generación espontánea de los animales después del diluvio gracias al calor del sol sobre la tierra húmeda y no hay nada que sugiera la idea de nitidez o transparencia.

Así pues, Fratantuono rechaza, con razón, la conjetura de Merkel y aboga por la restitución del transmitido caelo. En el comentario (p. 258-9), señala que se trata de un pasaje difícil y afirma que la clave de la interpretación reside en el término bulla. Ello da pie a una extensa nota sobre la bulla del ciervo de Cipariso (cf. 114) y la bulla que solían llevar los jóvenes aristócratas romanos. Sin embargo, la discusión se revela inútil para dar con la solución al problema textual, ya que Fratantuono acaba defendiendo la lección fulvo ... caelo con independencia del sentido de bulla. Así pues, habría bastado indicar que la bulla descrita por Ovidio podría evocar, atendiendo a la tierna edad de Adonis al morir, la bulla de los jóvenes romanos y del ciervo de Cipariso.

Sea como sea, el imaginario del símil muestra con claridad que aquí bulla significa sencillamente 'burbuja'. Ese sentido está también documentado en Plinio (nat. 31.12), Marcial (8.33.18) o Apuleyo (met. 4.6), y bien pudo ser su sentido originario?.

Pero la lección propuesta por Fratantuono, fulvo ... caelo, tampoco está falta de problemas. Anderson $(1972,535)$ apuntaba que Ovidio estaría hablando de una burbuja que se eleva en el cielo. Fratantuono, en líneas generales, da la misma interpretación y añade que (p. 259) ello podría estar presagiando el cometa de César (15.749) ${ }^{10}$. Pero de nuevo: ¿en qué circunstancias una burbuja suele elevarse en o hacia el cielo? Véase también Reed 2013, 301. Además, con surgere, el ablativo más que una dirección o un lugar generalmente indica el origen del movimiento o la causa del mismo (cf., e. g., am. 2.15.25, met. 2.771, 8.192, 9.702, 12.579, fast. 1.692, 5.228; cf. también fast. 4.830, 5.111).

En mi opinión, el problema queda resuelto si en lugar de fulvo leemos pluvio junto a una parte importante de los códices (muchos más de los que hay implícitos en el aparto de Tarrant). Esa fue, durante mucho tiempo, la lección preferida por casi todos los editores. El sentido del símil es el siguiente: Venus rocía el charco de sangre de Adonis con néctar exactamente de la misma forma en que la lluvia cae sobre un charco de agua cristalina, formando pequeñas burbujas. Ya Burman $(1727,741)$ vio la idea que hay detrás del símil:

${ }^{9}$ Cf. A. Ernout - A. Meillet, Dictionnaire étymologique de la langue latine: histoire des mots. Retirage de la $4^{\mathrm{a}}$ édition augmentée d'additions et de corrections par Jacques André, Paris, 2001, 78 s. v. bulla; A. Walde - J. B. Hofmann, Lateinisches Etymologisches Wörterbuch, 1938', I, 122 s. v. bulla; ThLL II 2241.39-57.

${ }^{10}$ Fratantuono cita el pasaje sin ofrecer la referencia exacta. 
"cum pluvia enim cadit in aquam, surgit bulla ex gutta" (cf. Luck 2005, 264). En efecto, es frecuente observar cómo, al llover, se forman pequeñas burbujas en los charcos. Es probable, pues, que debamos imaginarnos que la sangre de Adonis fue entumeciéndose en forma de pequeñas burbujas (cf. 734-5). Esas burbujas, evidentemente, pueden ser perlucidae y pueden representar bien la fragilidad de la anémona y la proverbial belleza de Adonis. Para la juntura pluvium ... caelum, cf. Varro rust. 1.13.2, Colum. 11.2.41; cf. también Verg. georg. 3.279 pluvio contristat frigore caelum. Creo, pues, que debemos leer pluvio ... caelo.

Dudas sobre la solución adoptada por Tarrant o preferencia por otra solución

En su comentario a algunos otros pasajes Fratantuono muestra preferencia por una solución textual distinta o expresa sus dudas sobre la elección de Tarrant.

50 Rhodopeius ... heros - Orpheus

Fratantuono no descarta, como el propio Tarrant, la variante Orpheus. Tarrant $(2004,285)$ basa sus dudas en la existencia del paralelo de ars 3.321 (Rhodopeius Orpheus). Fratantuono no menciona este importante dato y apoya sus dudas sólo en el valor de los mss. U y $\mathrm{P}$ (según las siglas de Tarrant). En mi opinión, la variante Orpheus es un ejemplo claro de glosa que ha sustituido la palabra original métricamente equivalente. La juntura Rhodopeius ... heros es un giro poético que fue glosado mediante el correspondiente Orpheus. Al ser heros y Orpheus indistintos prosódicamente, el término más concreto sustituyó al genérico sin ninguna dificultad. Es un caso análogo al verso 207, donde algunos mss. han sustituido heros por Aiax, también idénticos a nivel prosódico. Los dos ejemplos de Orpheus a final del verso (64 y 79), lejos de ser un argumento a favor de la variante alternativa, sólo pudieron acabar de facilitar la inserción de la glosa en el texto. Por contra, Fratantuono observó justamente que la juntura Rhodopeius ... vates (vv. 11-2) contribuye a establecer Rhodopeius ... heros como la lectura buena.

Debo señalar aquí que, como en este caso, de vez en cuando Fratantuono reproduce en el comentario la información del aparato de Tarrant (otras veces señala sólo la existencia de la variante in abstracto), pero sin ofrecer ninguna clase de conspectus codicum (aquí añade la información, más bien poco relevante, de que U y P se encuentran "in the Vatican and Paris"). La presencia en el libro de un sencillo listado de mss. no sólo habría ido en beneficio del rigor filológico, sino que también habría sido una manera sutil de ofrecer a los estudiantes un primer contacto con los textos críticos. Sin duda, debería ser una práctica estándard de cualquier edición o comentario escolar que aborde cuestiones de crítica textual.

58 certans - captans

Al parecer, Fratantuono considera posible la variante captans, aunque 
admite que certans es preferible por sentido. Sin embargo, el verbo captare no parece emplearse con infinitivo en la poesía augustea (los paralelos más autorizados para esta construcción no bastan para admitirla en Ovidio: Ciris $383^{11}$, Phaed. 4.8.6 y 5.3.2). Heinsius $\left(1659,259^{\mathrm{n}}\right)$ aportó dos paralelos sólidos que no dejan duda sobre la autenticidad de la variante minoritaria certans: fast. 1.213 y Sil. 13.653. No está de más subrayar que, de acuerdo con Tarrant (2004, 285), certans está respaldada por los mss. M B. ${ }^{12}$

115-6 parilesque ex aere - parilique aetate

Fratantuono pone en duda la impecable lectura parilesque ex aere y se inclina por la lección mayoritaria parilique aetate (cf. Tarrant 2004, 287), ya que le parece incoherente que las bacae sean de bronce. Pero lo cierto es que baca no necesariamente significa 'perla' (cf., e. g., Rhet. Her. 4.12 .18 si fugiemus crebras vocalium concursiones ... ut ... bacae aeneae amoenissime inpendebant'; Palad. 2.14.3; véase también ThLL II 1657.201658.26; Bömer 1980, 56). Además, la lección parilique aetate está lejos de ser buena, puesto que no parece la forma más idónea de indicar que el ciervo lleva la bulla desde su nacimiento (cf., e. g., Plin. nat. 8.119, Verg. Aen. 7.484; léase Bömer 1980, 55). Tampoco está claro por qué Ovidio precisaría este dato sólo para la bulla o las bacae y no para el resto de ornamentos. La lección aetate es probablemente, como ya indicó Hartman ${ }^{13}$, una interpolación a partir de 8.631. La lección ex aere tiene la ventaja de que es muy coherente con la descripción de los ornamentos que Ovidio ha realizado hasta el momento, indicando los materiales de cada uno de ellos, en una gradación de mayor a menor nobleza (cf. Gierig 1807, 80): cornua fulgebant auro (112), gemmata monilia (113), bulla argentea (114) y, finalmente, bacae ex aere (115-6).

184 repercusso ... pondere - repercusso ... ab aere

Tarrant $(2004,290)$, como otros editores antes que él, se inclina por la conjetura de $\mathrm{Koch}^{14}$ repercusso ... pondere para subsanar el incomprensible repercusso ... in aere de la mayor parte de los códices (algunos códices ofrecen la variante repercussum ... in aera, que daría sentido si no fuese porque en el verso siguiente leemos in vultus ... tuos sin conjunción alguna $\left.{ }^{15}\right)$. La conjetura de Koch o la alternativa de Merkel (1878, xxxi) repercusso ... verbere, así

${ }^{11}$ Sobre este lugar, véase R.O.A.M. Lyne, Ciris. A Poem attributed to Vergil, Cambridge, 1978, 264.

${ }^{12}$ Heinsius leyó certans en tres códices más y yo lo he leído también en el Neapolitanus Bibl. Naz. IV.F.2, f. $69^{\mathrm{r}}$, sigla R en la edición de Tarrant.

${ }^{13}$ J. J. Hartman, De Ovidio poeta commentatio, Lugduni Batavorum, 1905, 360 (= Mnemosyne 33, 1905, 360). Slater (D. A. Slater, Towards a text of the Metamorphosis of Ovid, Oxford, 1927, 88) y Tarrant $(2004,287)$ recogen la misma idea.

${ }^{14}$ H. A. Koch, "Coniectanea in poetas latinos", en Symbola philologorum Bonnensium in honorem Friderici Ritschelii collecta. Fasciculus prior, Lipsiae, 1864, 342.

${ }^{15}$ Heinsius $\left(1659,263^{\mathrm{n}}\right)$ trató de enmendar el pasaje cambiando in vultus por et vultus, pero la construcción resultante me parece igualmente difícil y dudosa, puesto que el sintagma in aera et vultus tuos queda interrumpido por el nominativo tellus. 
como otras propuestas parecidas, no son convincentes estilísticamente, pero tampoco desde el punto de vista paleográfico. Fratantuono parece inclinarse, junto a Bömer $(1980,78)$, por repercussum ... ab aere. Debería especificarse que se trata de una conjetura de Jahn ${ }^{16}$ a partir del Argentinensis de Heinsius $\left(1659,263^{\mathrm{n}}\right)$, en que se leía repercusso ... ab aere, variante que he encontrado también en el Francofurtanus Bibl. Civ. et Univ. Ms. Lat. Qu. 21, f. 135 ${ }^{\mathrm{v}}$ (s. $\mathrm{XV}$ ). La conjetura fue admitida también por Lafaye ${ }^{17}$. Sin duda, parece la mejor solución al problema textual, ya que ofrece un sentido bueno con un cambio mínimo. Cf. Sil. 10.623, Stat. Theb. 11.53 cum subitum obliquo descendit ab aere vulnus. Una construcción parecida se encuentra en $\mathrm{Ov}$. met. 2.311-2 dextra libratum fulmen ab aure/ misit in aurigam; trist. 1.1.72 venit in hoc illa fulmen ab arce caput.

325 dilectu (de- ?) - delicto

Fratantuono retoma en consideración la variante mayoritaria delicto, claramente inferior a delectu o dilectu (por cierto, la referencia "P has dilectu" es incorrecta; dilectu es la lectura del hasta hace poco perdido fragmentum Caesenas ${ }^{18}$; P, o sea el Vaticanus Palatinus lat. 1669, da dilecto, como bien señala Tarrant 2004, 295). La confusión entre di- o de-lectus y delictum es muy frecuente (cf. ThLL V.1429.78-79). Por otra parte, no está claro si hay que escribir dilectu o delectu, pero quizá es preferible la primera forma, si nos atendemos, entre otras fuentes, a ThLL V.11168.16-27. Léase también Heinsius a met. 14.678 ${ }^{19}$.

637 quod - quid facit ignorans amat

Fratantuono remite a Possanza ${ }^{20}$ y a Reed $(2013,52 ; 286)^{21}$, quienes han tratado de justificar de nuevo el solecismo quid facit, que Tarrant había evitado con buen criterio (cf. Merkel 1878, xxxII; Housman 1890, 148-9). El comentario de Fratantuono es confuso y no queda claro cuál es su opinión al respecto, pero sin duda la interpretación of recida de quid como why (p. 230) no parece posible. Se debería haber especificado, teniendo en cuenta el público al que está destinado el comentario, que quid plantea la dificultad de admitir

${ }^{16}$ P. Ovidii Metamorphoses recensuit varietate lectionis notisque instruxit Gottlieb Erdmann Gierig. Editio tertia emendata et aucta cura Joannis Christiani Jahn. Tomus posterior, Lipsiae, 1823, 99.

${ }^{17}$ Ovide, Les Métamorphoses. Tome II (VI-X). Texte établi et traduit par Georges Lafaye, Paris, 1928, 128.

${ }^{18}$ Cf. L. Rivero, "N. Heinsius' fragmentum Caesenas of Ovid's Metamorphoses rediscovered”, $C Q$ 66, 2016 [en prensa].

${ }_{19}$ Nic. Heinsii Commentarius in P. Ovidii Nasonis Opera Omnia, Lipsiae, 1758, II, 737; cf. Burman 1727, 992.

${ }^{20}$ M. Possanza, "R. J. Tarrant, P. Ouidi Nasonis Metamorphoses. Oxford Classical Texts. Oxford: Clarendon Press, 2004”, BMCRev 2005-06-27, ad loc. (http://bmcr.brynmawr.edu/2005/2005-06-27.html).

${ }^{21}$ Cf. F. Stock, "Review: Ovidio: Metamorphoses, Vol. 5 (Libri X-XII) a cura di Joseph D. Reed, traduzione di Gioacgino Chirarini [= Reed 2013]”, ExClass 18, 2014, 270. 
una interrogativa indirecta con indicativo, mientras que con quod lo que tenemos es una oración de relativo sustantivada (y que, por lo tanto, admite el indicativo sin problemas). Cuando Fratantuono afirma que el indicativo en la interrogativa indirecta añade vivacidad a la escena, en realidad está creando confusión y aduciendo una justificación banal del indicativo que pasa por alto el problema.

Tarrant $(2004,308)$ encontró la variante quod en el Sangallensis 866 (que Fratantuono cita de nuevo con la sigla $G$, sin ofrecer un conspectus $)^{22}$. Hay que señalar que quod no sólo evita el solecismo, sino que ofrece un sentido mucho más rico. Burman $(1727,734)$ glosaba: "amat; quod (sc. amare) ignorans facit et non sentit tamen amorem”. Cf. 14.491 quod facit, oderit omnes (cf. ThLL VI.1102.46-55; Bömer 1986, 169-70). No está de más señalar que la vacilación entre quid y quod es frecuente en los manuscritos, sobre todo a causa de la confusión de las abreviaturas.

719 agnovit longe gemitum - gemitus

Fratantuono apunta que la variante gemitus podría ser correcta (Tarrant 2004, 311: "gemitus $U P$ ”). Sin embargo, el uso del singular o del plural no presupone que debamos imaginarnos que la agonía de Adonis sea, respectivamente, más breve o más larga e intensa. En mi opinión, el quid de la cuestión reside en discernir si Ovidio reprodujo sin ningún cambio una frase virgiliana (Aen. 10.843 agnovit longe gemitum) o si la varió ligeramente alterando gemitum en gemitus (después los copistas habrían cambiado de nuevo gemitus por influencia del virgiliano gemitum). Como sucede con frecuencia en las alternancias entre singular y plural, es difícil zanjar el problema, pero yo me inclinaría más bien por el singular junto a la mayor parte de los mss. y por correspondencia con la expresión virgiliana. Así lo han hecho casi todos los editores.

\section{2 tactus}

Fratantuono califica tactus de "interesting crux", sin especificar cuál es su opción. En realidad el problema dista mucho de ser una "crux": cf., e. g., 11.498. El propio Housman $(1890,149)$, autor de la atractiva conjetura tinctus (a partir de la lectura de M tractus), admitía que, en relidad, no había ningún problema con tactus. La confusión entre tactus y tractus se produce también en $8.184^{23}, 8.224^{24}$ y trist. $4.5 .11^{25}$.

${ }^{22}$ He leído quod también en algunos otros códices: Berolinensis Deutsche Staatsbibl. Diez B Sant. 13 (ante correctionem), Glasguensis Mus. Hunterianus 266 (U.5.6), Phillippicus 9033 (Marstonianus Yalensis 47) (ante correctionem) y Berolinensis Deutsche Staatsbibl. Diez B Sant. 5.

${ }^{23}$ Cf. Burman 1727, 564.

${ }^{24}$ Cf. Tarrant 2004, 223.

${ }^{25}$ Cf. P. Ovidius Naso, Tristia herausgegeben, übersetzt und erklärt von Georg Luck, Band I: Text und Übersetzung, Heidelberg, 1967, 163. 


\section{Comentario sobre otras variantes textuales}

En algunos otros pasajes, Fratantuono comenta algunas de las variantes textuales que se encuentran en los manuscritos, aunque se muestra partidario del mismo texto que edita Tarrant. Llama la atención que en bastantes casos se trata de variantes claramente erróneas conservadas por lo menos en M. ${ }^{26}$

653 summam celeri pede libat harenam - summa celeris pendebat harena

Fratantuono señala que $\mathrm{M}$ en lugar de summam celeri pede libat harenam ofrece summa celeris pendebat harena, lo que, según él, da un sentido más fácil, pero quizá menos dramático. A mi modo de ver el texto de $\mathrm{M}$ sencillamente no da sentido (prueba de ello es que no ha sido aceptada ni por los editores más fieles a $\mathrm{M}$ ). La corrupción de $\mathrm{M}$ ( $\mathrm{y}$ de algunos otros códices ${ }^{27}$ se explica con facilidad a partir de la caída de la sílaba li- de libat (pede libat $>$ pede bat $>$ pendebat).

654 celeri - sicco ... radere - laedere

Creo que Fratantuono está en lo cierto cuando afirma que la variante celeri en lugar de sicco en 654, que no atribuye a ningún manuscrito (Tarrant

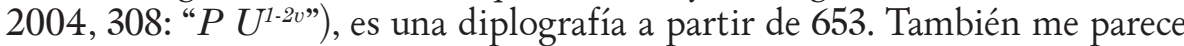
acertada la interpretación de la variante laedere en lugar de radere (de nuevo, no atribuida a ningún códice; cf. Tarrant 2004, 308: " $M\left(N^{a c}\right.$ ? $) S$ ") como una interpolación a partir de Verg. Aen. 7.809²8. Obsérvese, además, que la distancia paleográfica entre las dos variantes es muy poca.

673 muneris - numinis

Fratantuono dice que la variante numinis de M y S no da un sentido tan bueno como muneris; pero en realidad numinis está claramente excluido por sentido. Se trata de una confusión habitual en los códices.

678 impediique - impeditique

Fratantuono apunta que la variante de $\mathrm{M}$ impeditique en lugar de impediique "gives a less balanced description of the verbal action", pero impeditique en ese contexto es amétrico e inviable por sentido.

685 ipsa-ipsam

Estoy de acuerdo en que funciona mejor ipsa que la variante ipsam (Tarrant 2004, 309: “ipsa $M\left(N^{a c}\right) U F L P$ : -am $N^{2 c} S B G$ ”).

691 luminis - liminis

Fratantuono también acierta al inclinarse con decisión por luminis en

${ }^{26} \mathrm{Me}$ pregunto si ello podría ser influencia de la teoría, imperante durante un tiempo, pero ya superada, sobre la supremacía de M (Marcianus Florentinus 225): cf. A. E. Housman, $M$. Manilii Astronomicon Liber Primus, Londinii, 1903, xxxviii; J. R. Tarrant, "Review Article: Editing Ovid's Metamorphoses: Problems and Possibilities", CPh 77, 1982, 346; Anderson 1991, xii.

${ }^{27}$ Cf. Burman 1727, 736 .

${ }^{28}$ Véase la nota 4. 
lugar de las alternativas liminis y numinis (Tarrant 2004, 310: "luminis] lim- $S N^{c} U^{3 c} G L$ : num- $\left.M F^{\prime \prime}\right)$. Léase Burman 1727, 738.

710 suem - suis

Fratantuono considera mejor suem que la variante suis en 710 (cf. Tarrant 2004, 310: "suem $N^{2 c} U F^{3 c} P$ : suis $M N^{a c}(S)$ "), pero suis no me parece una opción válida, puesto que la omisión del objeto de excivere llevaría el texto al límite del anacoluto. Véanse, además, los vv. 711-6 y el comentario de Reed $(2013,294)$.

\section{4 at $-e t$}

Finalmente, Fratantuono comenta la alternancia entre at y et en 724 (Tarrant 2004, 311: "at $o l_{5} X$ : et $\Omega($ est $M)$ : sed Korn"), que no ofrece ninguna dificultad especial (obsérvese la presencia de tamen): cf. 8.279, 12.367-8, epist. 12.129, am. 3.7.1. Por contra, Fratantuono no dice nada a propósito de la misma alternancia en 728 , donde Tarrant $(2004,311)$ anotó con buen criterio: "at] et BFGL $U^{4}$, fort. recte". Al parecer G. Luck era partidario de et en $728 .{ }^{30}$ Pero probablemente hay que mantener at también en 728 como "lectio difficilior". La noción adversativa es débil, pero no ausente del todo.

Por otra parte, sorprende que, ante la promesa (p. vi, n. 1) de tratar las cuestiones textuales sensibles en el comentario, Fratantuono no comente nada a propósito, por ejemplo, de los versos 133, 239, 380, 423, 536, o que no advierta ni siquiera que las lecturas siguientes son conjeturas: 65 Stygii (Heinsius 1659, 260 $), 98$ tinus (Heinsius 1659, 261 ${ }^{\mathrm{n}}$ ), 221 abnuat (Heinsius $1659,265^{\mathrm{n}}$ ), 271 pandis (Heinsius 1659, 266-7 ${ }^{\mathrm{n}}$ y Gronovius; confirmada con posterioridad por algunos manuscritos), 308 sed et hic (Heinsius s1 $^{31}$, 105 alto (Bothe ${ }^{32}$ ), 584 insidiasque (Shackleton Bailey 1981, 335). También sorprende que se pase por encima de 191 horrentia (Fratantuono da la lección como segura sin mencionar a Riese ${ }^{33}$, el autor de la conjetura; en mi opinión, es muy superior la conjetura florentia de Ramírez de $\operatorname{Verger}^{34}$ ) o que no se diga casi nada sobre corrupto verso 225 . No estaría de más algún comentario adicional sobre la atetización de los versos 200-1, 205-8 (con la nota de Fratantuono, p. 117, no queda claro qué versos se ven afectados), 256, 305, 549. Por lo

${ }^{29}$ Léase Heinsius ad loc. (P. Ovidi Nasonis Operum tomus I. Scripta Amatoria complexus. Nicolaus Heinsius, D. f., infinitis locis castigavit ad fidem scriptorum exemplarium, Amstelaedami, 1661, 96-7n).

${ }^{30}$ Así consta en A. Ramírez de Verger, Publio Ovidio Nasón. Obras completas, Madrid, $2005,1958$.

${ }^{31}$ Berolinensis Diez. $4^{\circ} 1075$, f. 288 ; cf. Burman 1727, 719. Al parecer Magnus hizo la misma conjetura por cuenta propia: H. Magnus, "Neue Studien zur Überlieferung und Kritik der Metamorphosen Ovids", Hermes 39, 1904, 47-8.

${ }^{32}$ Friderici Henrici Bothe Vindiciae Ovidianae sive Annotationes in P. Ovidii Nasonis Metamorphoseon libros XV, Gottingae, 1818, 104-5. 1872, XXI.

${ }_{33}$ P. Ovidii Nasonis Carmina edidit Alexander Riese. Vol. II: Metamorphoses, Lipsiae,

${ }^{34}$ A. Ramírez de Verger, “Lilia in Ovid, Metamorphoses, 10,191”, Maia 61, 2009, 101-6. 
general, Fratantuono se limita a decir que Tarrant los atetiza, pero no da su opinión (sólo a propósito de 200-1 dice que la atetización es una cuestión subjetiva, lo que me parece cierto). Sea como sea, en su texto Fratantuono no usa nunca corchetes, de modo que quizá deberíamos deducir que no considera interpolado ningún verso.

\section{Otras consideraciones}

Formalmente, sorprende que Fratantuono haya decidido prescindir de cualquier signo de puntuación para señalar el discurso directo. Por mucho que el poeta emplee marcadores como ait, inquit o dixit (cf. p. 215), es evidente que la falta de comillas puede dificultar la interpretación del texto, sobre todo a los lectores noveles para los que está pensado el libro (cf., e. g., 275-6 “[...] sit coniunx, opto", non ausus "eburnea virgo"/ dicere Pigmalion "similis mea” dixit "eburnae."; 320; 412; 429; 463-4; 564; 569; 657; 724). Todavía más grave me parece que el comentario, lejos de subsanar esta deficiencia, obvie otras dificultades, o peculiaridades, como el "-que Ovidianum” del v. 543 (monet "fortis"que "fugacibus esto") o su lógica extensión 35 en el verso 569. Asimismo, es llamativo que el comentario no diga nada, por ejemplo, a propósito de las dos interpretaciones que pueden emerger de los vv. 556-7, según se interprete que el discurso directo acaba en un lugar u otro, cuando éste era uno de los objetivos que Fratantuono perseguía al suprimir las comillas (cf. p. vii, n. 3). En los versos 640-1 la falta de comillas y otros signos de puntuación deja la construcción sintáctica en la ambigüedad y Fratantuono tampoco da cuenta de las dos interpretaciones posibles (cf. Bömer 1980, 211).

Por otra parte, es una lástima que el texto latino no venga acompañado de una traducción que diera una idea de exacta de cómo Fratantuono lo entiende. Ello habría resuelto, por lo menos en parte, la interpretación de algunos pasajes "difíciles" y habría evitado la proliferación de comentarios o notas que se limitan a traducir o a parafrasear el texto, como veremos en las páginas 214-5.

En último lugar, debo señalar que el texto latino no está libre de erratas. Algunas de ellas son graves y comprometen la intelección del texto: e. g. 133 lēniter en lugar de lëviter; 301 mulcebant en lugar de mulcebunt; 321 debe puntuarse di, precor,; 335 resolvor en lugar de revolvor; 356 después de dixerat sería preferible una puntuación fuerte, como hace Tarrant; 405 quodcumquest parece también una errata; 464 Cinyre en lugar de Cinyra (falta también una coma después del vocativo); 501 robora en lugar de robore; 523 ipse en lugar de ipso ${ }^{36} ; 549 ; 623$ hay que añadir ante después de iam; 667

${ }^{35}$ Cf. A. E. Housman, "Ovids Heroides [5]”, CR 11, 1897, 426-7.

${ }^{36}$ En realidad, ipse es la variante, no señalada por Tarrant en su aparato, de algunos mss. (cf. Burman 1727,726), entre los cuales el Vaticanus Urbinas lat. 341, el Erfurtensis Amplon. f. 1 o el Hauniensis Bibl. Reg. Gl. kgl. S. 2008. Dado que Fratantuono no menciona la existencia de la variante o su discrepancia respecto al texto de Tarrant interpreto su ipse como un lapsus calami. 
corpus en lugar de cursus; 677 pondere en lugar de pondera; 681 dignaque en lugar de dignane; 706 pugna en lugar de pugnae.

\section{El COMENTARIO}

No me cabe duda de que es una buena práctica en un comentario ir reproduciendo paulatinamente el texto que es objeto de estudio. En este caso, Fratantuono ha decidido, de forma loable, repetir todo el texto, verso a verso. Pero seguramente habría sido preferible agrupar los versos por unidades de sentido, de modo que no fuera necesario ofrecer un comentario para todos y cada uno de los versos con independencia de que la aportación resulte o no relevante.

\section{Comentarios prescindibles}

Fratantuono afirma (p. vii) haber evitado adrede la elaboración de un vocabulario para estimular el uso del diccionario. Sin embargo, dedica mucho espacio a traducir palabras y expresiones que no plantean dificultad alguna o cuyo significado se puede encontrar fácilmente en cualquier léxico (e. g. 25 pati; 31 properata ... fata; 33 serius aut citius; 34 huc; 53 acclivis; 167 ante omnes; 171 retia; 190 riguo; 213 argenteus; 299 felices; 302 fides; 334 nasci; contigit; illic; 335 laedor; 336 amari; 389 tuetur; 475 caecae munere noctis; 478 palmiferos; 497 non tulit ... moram; 502 erile; 511 puerpera; 522 formosissimus; 531 piscosam; 608 Hippomene victo; 613 me iudice; 619 fors ... dura; 668 resonant; 687 nemorosis; abdita; 689 illic; 707 virtus; 720 illuc; 722 desiluit).

Asimismo, con demasiada frecuencia las notas parafrasean el texto. Por ejemplo, en 61 questa, Fratantuono señala que el verbo aparece en contraste con el parentético quereretur y comenta: "Eurydice had nothing to complain about except that she was loved by Orpheus", que es esencialmente lo que dice el texto en 60-1 non est de coniuge quidquam/ questa suo (quid enim nisi se quereretur amatam?). Los ejemplos son muy numerosos: e. g. 11 Rhodopeius; 26 supera; 28; 35 longissima; 37 munere; 387-8; 414; 437; 485; 541; 543; 546; 547; 554; 562 enim; 566; 567 sorte; $588 ; 597$ hospes; 615; 617; 625 taedia vitae; 632 nollem ... fuissem; 646 dotem; 654 sicco; 666; 667; 678 pariter; 683 subitam ... iram; 684 dolens; 690 concita nostro; 695 temerat; probro; 701 verruntur; 704; 711;727; 735 facta mora est; concolor.

En otros casos, Fratantuono completa el texto o la paráfrasis con aportaciones banales y superficiales (e. g. 3 voce vocatur; 7 nullos ... ignes; 21 villosa colubris; 24 crescentes ... annos; 28 veteris ... rapinae; 32 iustos ... annos; 40 nervos; 53 silentia; 62 auribus; 64; 150 victricia; 155 quondam; 158 sua fulmina; 403 concipit; 406 gremio ... anili; 464 devotaque corpora; 487; 489; 494 pellis; 495; 503 infans; 508; 510; 5134; 518 leves; 531; 535 dumosa; 544 audaces ... audacia; 567 opacas; 568 vivit; 600 deterritus; 606 Neptunus; 612 carae ... vitae; 618; 620 thalamos 
... cruentos; 622 a sapiente puella; 626; 629; 637 tacta; 643 fateor; 650 videnda; 671 secundi; 672 virum; 673 muneris; 673 auctor; 675 iuvenaliter; 676 visa est; 676 coegi; 677; 679; 683; 693; 699; 701 harenae; 703; 715 inguine; totos; 718; 720 aethere; 722 pariter; 730 heros; 731 fata; 734 plena; 736 lento). En otros casos sus aportaciones son sencillamente intrascendentes. Por ejemplo, en 338 Cinyrae ... Cinyrae apostilla "Myrrha repeats the name of the object of her unlawful affections", lo cual es obvio y no aporta nada de nuevo. Habría sido deseable indicar que el primer Cinyrae es genitivo y el segundo dativo, y señalar cuál es el valor estilístico de este tipo de repeticiones ${ }^{37}$. Este tipo de comentarios tampoco son inusuales (e. g. 10 in talum; 15 Persephonen; 471 postera lux; 481 uteri ... onus; 557 requievit; 644; 657 dicentum; 686 templa; 708).

Asimismo, también me parece innecesario que se comenten de forma más o menos sistemática los sintagmas encabalgados en frontera de verso, pero de nuevo sin aludir al valor estilístico de este recurso (e. g. 1-2 immensum ... aethera; 70-1 iuctissima ... pectora; 153-4 inconcessis ... ignibus; puellas ... attonitas; 490-1 obliqua ... radix; 510-3 vivum ... onus; 640-1 ausis ... nostris; 646-7 templis ... meis; 698-9 levia ... colla; 719-20 albas ... aves $)^{38}$. Como ya he dicho, una traducción del texto habría resuelto de forma más económica las posibles dificultades que cualquier dislocación de los constituyentes de la frase pudiera suscitar, al mismo tiempo que se habría dado algo más de margen a los estudiantes para determinar por sí solos la construcción sintáctica de cada pasaje.

Por otra parte, no creo que en un comentario se deba dedicar espacio a cuestiones que cualquier gramática básica debería poder solucionar. En este sentido, me parece particularmente chocante que se traten cuestiones sintácticas que son normativas en la lengua clásica, al mismo tiempo que se guarda silencio sobre lo que se sale de la norma. Por ejemplo, en los vv. $235,278,346,357-8,364,372$, 413 se habla del uso del subjuntivo en las interrogativas indirectas, mientras que no se hace mención del uso del indicativo en 393 y 405. De nuevo, en 610 (dubitat, superari an vincere malit) Fratantuono destaca el uso del subjuntivo, cuando quizá sería más interesante explicar que se trata de una doble interrogativa indirecta. En 258, después de nada más ni nada menos que metuit ne, Fratantuono llama la atención sobre el uso del subjuntivo y, en 442, llama la atención sobre el indicativo con un $u t$ temporal.

No me parece menos desconcertante que Fratantuono señale hasta 6 veces que la desinencia de perfecto -ere es equivalente a-erunt (vv. 43, 75, 458,

${ }^{37}$ Cf. Wills 1996, 272-8; 391-4. Véase también M. Janan, “The Book of Good Love? Design Versus Desire in Metamorphoses 10", Ramus 17, 1988, 126.

${ }^{38}$ En algunos otros casos, sin un criterio evidente, Fratantuono explicita la concordancia entre elementos no contiguos dentro de un mismo verso, generalmente entre un adjetivo y su sustantivo (e. g. 84 teneros ... mares; 159 percusso ... aere; 188 animam ... fugientem). 
$514,646,647)$ o en otras 6 ocasiones que la desinencia -re de la segunda persona del singular de la voz pasiva es alternativa a -ris (vv. 141, 206, 348, $398,553,604)$, pero que no advierta nada sobre estas mismas formas en otros versos $(82,223,307,429,489,548,711$; cf. 658$)$. Sucede lo mismo con las formas de la declinación griega. Se analizan morfológicamente algunas (e. g. $2,12,15,31,217,220,279,651)$, pero ni se mencionan sus propiedades métricas ni se dice nada sobre muchas otras (e. g. 77, 150, 162, 169, 183, 196, 221 Propoetidăs, 238 Propoetidĕs, 530, 608 Hippomenē [ablativo], 718).

Asimismo, si se clasifican ablativos de tipos frecuentes como el separativo, el instrumental o el comparativo (e. g. vv. 8, 520) se podría señalar que trunco ... alto (105) y cortice (494) son ejemplos del llamado ablativo resultativo, que no es de los más usuales. Tampoco estaría de más indicar que cuiquam (576) y mihi (585) son dativos agente.

Seguramente el comentario tampoco es el lugar idóneo para explicar cuestiones como el origen morfológico de la desinencia $-\bar{a}$ del ablativo singular de la primera declinación (p. 50; luego, además, no se habla del origen de ninguna otra desinencia), el funcionamiento de la consecutio temporum (p. 56) o los usos de los tiempos verbales (pp. 205-7). Tampoco creo que haya necesidad de definir en el comentario el término "enclítica", y menos aún si la definición se da hacia el final del libro (p. 230). Probablemente, también es superfluo explicitar que verbos como 428 potiri y 658 uti (cf. 14) se construyen con ablativo o que quis equivale a aliquis después de partículas como si o ne (vv. 233, 483, 542, 583).

Por otra parte, viendo el tipo de comentarios en los que se complace Fratantuono, me extraña que no aprovechara para señalar en 401 que el verbo vivit concuerda, como es frecuente en latín, sólo con uno de los sujetos (genetrixque paterque) o que en 706 no ofreciera alguna explicación sobre la silepsis que implicaría la variante quod ... praebent en lugar de quod ... praebet (Fratantuono se limita a decir que Tarrant la considera posible, pero que el sentido no cambiaría; por otro lado, no parece que haya paralelos seguros para una silepsis de este tipo).

\section{Pasajes que se deberían comentar o enfocarse de forma distinta}

Ante una nómina tal de comentarios superfluos o prescindibles, sorprende que Fratantuono guarde silencio en otros pasajes en que incluso un lector más avanzado habría agradecida una ayuda. Veamos algunos ejemplos.

En el v. 32 (omnia debemur vobis), debería hablarse del uso medio del verbo y de omnia como acusativo de relación o, alternativamente, como sujeto concordando "ad sensum". La remisión al verso 18 es insuficiente.

En los vv. 32 y 633 se debería decir que quod actúa como partícula de enlace.

El texto de los vv. 143-4, tal como está editado, es difícil: ferarum/ concilio medius turba volucrumque debe entenderse como medius 
concilio ferarum et turba volucrum. Por ello, me parece claro que debe editarse turbae junto a parte de los mss. y puntuar ferarum/ concilio, medius turbae, turba volucrumque, según la propuesta de Bentley ${ }^{39}$ y Wakefield ${ }^{40}$. Léase Luck 2005, 263; 2008, 57-8. Hay que añadir que el texto aparecía ya con esta puntuación en las editiones Gryphianae de 1543, 1546, 1559 y $1565^{41}$. En la ed. Gryphiana de $1539^{42}$ aparece también esa puntuación, pero se lee turba.

En 427-8 (at virgo scit se non falsa moneri, / certa mori tamen est, si non potiatur amore) Fratantuono observa que at es una partícula adversativa fuerte, más intensa que sed, pero sorprende que no advierta, como sí hace Reed (2013, 250), que la frase virgo scit se non falsa moneri está en consonancia con las frases precedentes y que el contraste no llega hasta certa mori tamen est. Se esperaría, por lo tanto, una construcción equiparable a 7.425-6, am. 2.11.33-4 o Pont.1.3.47-8. Sin duda, hay que seguir a Capoferreus ${ }^{43}$ y leer et, que es, en realidad, la lectura de unos pocos manuscritos, entre los cuales el Parisinus lat. 8001, como ya atestiguó Anderson (1991, 243).

El sentido de motu en 455 no es evidente ${ }^{44}$, como tampoco lo es el de mors parata en $384^{45}$; también merecería una nota el uso del verbo complecti en $483^{46}$ o la frase est honor et lacrimis en 501. Asimismo, quizá convendría especificar que en 552 quae causa roganti hay que sobreentender sit.

${ }^{39}$ Edmund Hedickii Studia Bentleiana. V Ovidius Bentleianus, Freienwaldiae, 1905, 31.

${ }^{40}$ T. Lucretii Cari De Rerum Natura Libros Sex, ad exemplarium mss. fidem recensitos, longe emendatiores reddidit...cum animadversionibus...Gilbertus Wakefield, Londini, 1796, I, 9 .

${ }^{41}$ Pub. Ovidii Nasonis Metamorphoseon libri XV, cum indice fabularum locupletissimo. Lugduni apud Seb. Gryphium, 1543, 282; Pub. Ovidii Nasonis Metamorphoseon libri $X V$. Denuo collatis probatissimae fidei exemplaribus quam accuratissime emendati. Apud Seb. Gryphium, Lugduni, 1546, 258; Pub. Ovidii Nasonis Metamorphoseon libri XV. Denuo collatis probatissimae fidei exemplaribus quam accuratissime emendati. Apud Seb. Gryphium, Lugduni, 1559, 258; P. Ovidii Nasonis Metamorphosewn libri XV. Denuo collatis probatissimae fidei exemplaribus quam acuratissime, variis lectionibus ad marginem appositis, emendati. Lugduni, apud Antonium Gryphium, 1565, 286.

${ }^{42}$ Pub. Ovidii Nasonis Metamorphoseon, hoc est, Transformationum, libri XV, cum indice fabularum locupletissimo. Lugduni apud Seb. Gryphium, 1539, 256.

${ }^{43}$ Joannis Gulielmi Capoferrei Animadversionum in auctores classicos L. L. Liber I qui est in Ovidii Metamorphosin, Lipsiae, 1659, ad loc.; cf. Burman 1727, 1099.

${ }^{44}$ Prueba de ello es que algunos códices sustituyeron motu por tactu (cf. Burman 1727, 722), que ha sido defendido por Liberman 2004, 79, y que a mí me parece inferior poéticamente.

${ }^{45}$ Luck $(2008,58)$ sugirió leer mortisque parata/ instrumenta en lugar de mortisque paratae/ instrumenta. Burman $(1727,717)$ atestiguó la variante parata en dos mss., pero a mí me parece "lectio facilior": cf. 390 tardae conamina mortis; Sen. Herc. f. 1027-8; Lucan. 5.773-4; 8.32; Apul. met. 10.5.2.

${ }^{46}$ Algunos mss. sustituyeron complexa, un uso metafórico prácticamente sin paralelos (cf. ThLL III 2086.18-47; pero léase Bömer 1980, 161), por el más convencional exorsa, admitido por Burman $(1727,723)$. Liberman $(2004,79-80)$ conjeturó molita, que me parece muy poco probable. 
Un verso relativamente difícil como 591 habría requerido un comentario más focalizado en el sentido del conjunto y no sólo sobre talaria. Por cierto, hay que precisar que talaria significa más bien "wings at the ankles" y no "winged sandals", como bien demostró Anderson ${ }^{47}$.

En 493 Fratantuono traduce el no particularmente problemático sucos (cf. OLD 1968, 1859 s. v. 3), pero desaprovecha la oportunidad de comentar el caso de "simplex pro composito" que hay en el verso (Reed 2013, 263): la expresión habitual no es ire in, sino abire in.

Por otra parte, no estaría de más haber especificado que la oración de relativo sustantivada de 581 (Fratantuono habla de unos vagos "initial relative pronouns") actúa como un vocativo o, alternativamente, como sujeto de 580 ignoscite.

Habría convenido ofrecer la traducción de 624 viderit!, ya que se trata de una expresión un tanto particular (cf. OLD 1968, 2059 s. v. video 18b). Sea como sea, en mi opinión, es preferible la interpretación de la expresión como futuro anterior ${ }^{48}$, aunque son muchos los que lo entienden como un perfecto de subjuntivo.

En el verso 628 (non erit invidiae victoria nostra ferendae) habría convenido señalar de forma explícita que non se refiere a ferendae, como bien han apuntado algunos comentaristas (e. g. Anderson 1972, 527; Bömer 1980, 208; cf. Reed 2013, 285).

En otros casos, los comentarios de Fratantuono deberían ser matizados o completados.

Por ejemplo, en 15 inamoena se advierte, acertadamente, que el adjetivo es probablemente una creación ovidiana, pero habría sido apropiado añadir que no se trata de un procedimiento en absoluto inusual ${ }^{49}$.

En 352 la construcción arcaizante ne concipe se comenta debidamente. Pero habría sido útil contrastarla con 302 , donde Ovidio emplea la construcción nec con imperativo, normal en la lengua clásica ${ }^{50}$.

En 361 haec se refiere probablemente también al aestus (360). Véase Bömer 1980, 134. Ovidio probablemente emplea el verbo aestuare en el doble sentido de 'arder' de amor y 'vacilar'.

${ }^{47}$ W. S. Anderson, "Talaria and Ovid Met. X 591", TAPhA 97, 1966, 7-12.

${ }^{48}$ Cf. H. Blase, "Tempora und Modi”, en G. Landgraf (ed.), Historische Grammatik der lateinischen Sprache, III. Syntax des einfachen Satzes, Leipzig, 1903, 183-5; R. Kühner - C. Stegmann, Ausführliche Grammatik der Lateinische Sprache. Zweiter Teil: Satzlehre, 5. Auflage mit Zusätzen und Berichtungen von A. Thierfelder, Hannover, 1976, I, 148-9.

${ }^{49}$ Cf., e. g., Housman 1890, 148; A. Draeger, Ovid als Sprachbildner, Aurich, 1888, 8-10; Ae. Linse, De P. Ovidio Nasone vocabulorum inventore, Lipsiae, 1891, 49-50; J. C. McKeown, Ovid. Amores. Text, prolegomena and Commentary. Volume II: A commentary on Book one. Leeds, 1998, 195-6; E. J. Kenney, "Ovid's language and style”, en B. W. Boyd (ed.), Brills Companion to Ovid, Leiden - Boston - Köln, 2002, 27-89.

${ }^{50}$ Cf. A. Szantyr, Lateinische Grammatik, Band II: Syntax und Stilistik, München, 1972, 336-8. 
En 443 vicimus Fratantuono remite al artículo de W. Clarke, "Myrrha's Nurse: The Marathon Runner in Ovid?”, CPh 68, 1978, 55-6, pero se olvida de mencionar que vicimus es una expresión empleada con frecuencia en contextos similares (cf., e. g., 4.356, 6.513), y pasa por alto el hecho de que el artículo de Clarke se basa en un autor más tardío como Luciano de Samosata.

En el v. 450, Fratantuono apunta que probablemente la similitud entre los nombres de Mirra y Mera, el perro de Erígone, proporcionó a Ovidio la idea de contraponer Mirra y Cíniras con Ícaro y Erígone. Dudo que fuera así. Sin duda, lo importante es que Erígone es el modelo ideal de pietas filial (cf. 451 pio sacrata parentis amore; Manil. 2.31-2 pietate ad sidera ductam / Erigonen).

El comentario al v. 500 pasa por alto que el verso es relevante porque las lacrimae de Mirra se corresponden con las lágrimas de mirra que el árbol exuda espontáneamente.

En 574 legem, Fratantuono resalta, no sin razón, que el lenguaje reitera y subraya la naturaleza vinculante e inflexible de las reglas de la competición entre Atalanta y los pretendientes. Evidentemente, la comparación con 50-2 habría sido muy pertinente.

En la p. 216, Fratantuono destaca que se repite sorprendentemente decorem a final de dos versos consecutivos (589 y 590), pero en realidad no es un fenómeno tan sorprendente y excepcional como se sugiere: cf. Wills 1996, 418-23.

En el verso 609 Fratantuono ofrece algunas pinceladas sobre la intrincada cuestión de las duae Atalantae. Pero se echa en falta por lo menos la referencia al pasaje de Pseudo-Apolodoro que trata el mito (3.9.2) y unas referencias bibliográficas más precisas que las ofrecidas en las pp. 204-51.

El comentario al verso 725 es genérico: en realidad, se podría aplicar a casi cualquier divinidad que transforma a un ser por amor o compasión. En el mismo libro décimo, la metamorfosis de Jacinto por parte de Apolo podría merecer este comentario, incluso con más propiedad (cf., e. g., 202-8).

En 729 Fratantuono ofrece un correcto resumen sobre la problemática del mito de "Menta". No obstante, dudo que la historia fuese desconocida al público de Ovidio, como sugiere Fratantuono. No es el único caso en el libro décimo en que la historia narrada o aludida resulta oscura a los lectores modernos: es el caso de los Cerastas (220-37), las Propétidas (238-42), Letea y Oleno (68-71) o la alusión de los vv. 65-7, como ya ha ido señalando el propio Fratantuono.

Por otro lado, las notas que exploran las relaciones intertextuales, particularmente con Virgilio, suelen ser correctas (cf., e. g., 475, 608

${ }^{51}$ Un buen resumen del estado de la cuestión puede leerse en J. Barringer, "Atalanta as a Model: The Hunter and the Hunted", ClAnt 15, 1996, 48-9; K. Ormand, The Hesiodic Catalogue of Women and Archaic Greece, Cambridge, 2014, 120-22. 
memorabile nomen). Es muy pertinente, por ejemplo, la comparación de los rituales mágicos que la nodriza propone a Mirra (397-9) con los empleados por Dido en su furor por Eneas (Verg. Aen. 4.474-93). Sin embargo, las notas de Fratantuono en ese sentido no son sistemáticas y se dejan de señalar algunos loci paralleli relevantes. Así, en 369-70 igni/ carpitur indomito habría sido interesante resaltar la alusión a Verg. Aen. 4.2 caeco carpitur igni [Dido]. En el mismo verso 370, sobre furiosa, Fratantuono destaca que el lenguaje de la furia recurre en el episodio (efectivamente, así es: cf. 355, 397, 410), pero debería haberse añadido que el furor se atribuye también a Dido (cf., e. g., Verg. Aen. 4.101).

Paralelamente, hay que censurar que muchas veces Fratantuono no ofrezca las referencias exactas de los pasajes a los que remite. Por ejemplo, en 593 picto ... limbo leemos "In Vigil's Aeneid Dido is similarly dressed with an "ornamental border" (OLD s.v. a)", refiriéndose a Verg. Aen. 4.137. En 642, Fratantuono compara pertinentemente la recepción de la plegaria de Hipómenes con la de Arrun en el libro undécimo de la Eneida, pero no costaba nada remitir a los versos exactos (785-98). De forma parecida, en 648, debería indicarse que el árbol de oro del libro sexto de la Eneida se describe en los vv. 201-9.

También las notas que ponen de manifiesto los lazos estructurales o temáticos de la obra son, por lo general, correctas (e.g. 13 ausus; 14 simulacra; 264; 518,525 y $528 ; 567$ innuba), siguiendo el camino emprendido en la introducción. He encontrado particularmente sugerente el juego que se insinúa entre el sentido etimológico de coniunx en 571 y el hecho de que Atalanta e Hipómenes acaben transformados en leones enyugados. Es posible, no obstante, que la observación hubiese sido más pertinente a propósito de la respuesta del oráculo en los vv. 564-6.

También es interesante el comentario a 702, donde Fratantuono observa que la "ira" que se atribuye a los leones es una reminiscencia de la ira de la diosa hacia Hipómenes y Atalanta (cf. 683); pero hay que decir que esa misma idea se explota con mucha más pertinencia y profundidad en el comentario de Reed $(2013,293)$.

Sin embargo, algunas veces, como ya hemos visto, Fratantuono abusa del mecanismo y traza paralelismos un poco a la ligera sacando conclusiones precipitadas y poco argumentadas. Por ejemplo, me parece exagerado vincular la mera aparición del vocablo genetrix (vv. 332, 401) con la diosa Venus como "madre de los romanos", por mucho que Venus genetrix sea una juntura relativamente habitual. Tampoco creo se pueda relacionar la alusión al "lejano oeste" de 478 con la Pax Augusta, por lo menos no sin una argumentación sólida apoyada con evidencias textuales consistentes. En el mismo sentido, puedo decir que me cuesta ver en 649 decerpta una alusión clara a 5.536-8 (por mucho que la granada aparezca también en los versos conclusivos del libro).

Igualmente, me parecen muy forzadas algunas supuestas alusiones de carácter biográfico o metaliterario. Así, no creo que 397 carmine se pueda 
vincular con los famosos carmen et error (trist. 2.207), que no tienen nada que ver con el verso que nos ocupa ni por sentido ni por cronología. La referencia a 14.20-2, obtenida de Reed (2013, 248), era más que suficiente para ilustrar la frase ${ }^{52}$. De forma parecida, es claramente arbitrario sugerir, en el verso 715, que la reacción de Venus ante la muerte de Adonis por parte del jabalí representa la tensión entre épica y elegía, por mucho que se pueda sugerir la comparación con am. 3.9.15-6 (nec minus est confusa Venus moriente Tibullo/ quam iuveni rupit cum ferus inguen aper) y que se cite un artículo de Reed sobre el asunto (J. D. Reed, "Ovid's Elegy on Tibullus and Its Models", CPh 92, 1997, 260-9).

En esa misma línea, me parece dudoso, como ya he dicho, que en el libro décimo se pueda detectar, como un elemento central, un interés del poeta por cuestiones etnográficas, filosóficas o políticas, sobre las que Fratantuono insiste en el comentario. Es ilustrativo el caso del comentario a 659 Megareius. Fratantuono insiste en que el énfasis en los patronímicos y en la genealogía muestra el interés del poeta por la onomástica y las cuestiones relacionadas con la etnografía. Sugiere la comparación tan sólo con 660 Schoeneia, aunque podría haber remitido también a 605-6, 609 y 617, y quizá a 306, 309 (donde el mismo Fratantuono comenta ya algo sobre la cuestión), además de a la p. 10 de la introducción. Pero obsérvese que en otros lugares, sobre los que Fratantuono no dice nada, Ovidio no es tan preciso o cuidadoso. Me refiero en particular a la prolepsis de 290 Paphius ... heros (Pafos no nace hasta unos versos más abajo, en 297) o al repentino oscilar de la acción del episodio de Mirra entre Chipre y Asia (cf. 298, 306-10, 316, 418, 480)53. Todo ello me permite afirmar que el interés de Ovidio por estas cuestiones es básicamente tangencial, en tanto que se trata de elementos tradicionales que confieren verosimilitud al relato y que le consienten no repetir en exceso los nombres de sus personajes o escenarios.

\section{Imprecisiones}

El comentario contiene algunos errores e imprecisiones que convendría haber evitado.

En primer lugar, saltan a la vista un par de identificaciones morfológicas erróneas: en 158 Fratantuono dice que "the present subjunctives are in a present contrafactual conditional sentence", pero en el texto no hay ningún presente de subjuntivo (157 mallet; 158 dignatur; posset); 622 nolet se analiza como un imperfecto de subjuntivo, pero es un futuro imperfecto; 400 rear se analiza como "future indicative active", pero se trata del presente de subjuntivo de un verbo deponente.

${ }^{52}$ Cf. también am. 3.7.28, met. 14.357, 15.326, fast. 2.425-6, Lucan. 6.822. Léase Bömer 1980, 141.

${ }^{53}$ Evidentemente, el lector hará bien en ignorar estas pequeñas incoherencias, si es que las percibe, ya que no afectan en nada la calidad de la obra. 
En otros casos, la traducción de un término o la interpretación de un pasaje es errónea: 161 invitaque debería traducirse como "though Juno was unwilling"; se atribuye a 595 praestrinxerat el significado de "had grazed", que se corresponde, en realidad, con la variante textual perstrinxerat. Sobre el primer miembro del tricolon 387-8 tum denique flere vacavit, / tum dare complexus laqueique requirere causam, Fratantuono parafrasea erróneamente: "the nurse gives time to weep". Una simple ojeada a la traducción de la colección Loeb (Goold 1984,91), por ejemplo, le habría evitado el error: "then at last she [i. e. the nurse] has time to weep". La traducción de 467 aetatis ... nomine "with the name of her age" no parece adecuada. Es preferible entender nomine en el sentido de "a professed reason, pretext [...] on pretext (of)' (OLD 1968, 1186 s. v. nomen 15b). A propósito del verso 502 (nulloque tacebitur aevo), Fratantuono llega a afirmar que "there will be silence in no age", puesto que "the tears that still fall create their own sound". Pero las lágrimas no producen ningún sonido. El sentido de la frase está bien capturado, de nuevo, por la traducción de la Loeb (Goold 1984, 99): “and will be remembered through all the ages". 713 pando ... rostro, expresión que no me parece necesario traducir en el comentario, no significa "flat snout", sino más bien lo contrario "curved snout" (cf. Goold 1984, 115).

De forma parecida, en 223 Fratantuono (p. 121) habla de los Cerastae como si pudiera tratarse de mujeres; pero en el verso anterior los Cerastas aparecen anticipados por el pronombre masculino illos. En 335 quid in ista revolvor [no resolvor], Fratantuono indica "probably with fortuna understood", pero aunque fortuna aparezca en la frase anterior ista no dejará de ser un neutro plural que muy probablemente recoge buena parte de lo que Mirra ha dicho en su monólogo hasta el momento.

En algunos otros pasajes la interpretación del texto tampoco parece exacta o correcta.

En el verso 72 debe descartarse que portitor pueda referirse al Cerbero. La alusión es a Caronte.

En el texto, entre 466 timentem y 472 amantem, no me parece que haya nada que ponga de relieve que el miedo de Mirra va disminuyendo a cada encuentro con su padre, como sugiere Fratantuono en 472, aunque el lector es libre de imaginárselo.

584 insidiasque timet, según Fratantuono, significa que Hipómenes teme los trucos que Atalanta pueda emplear para vencer a los competidores, lo cual es absurdo porque Atalanta no necesita servirse de ninguna argucia para ganar (cf., e. g., 587-93) y porque Hipómenes no tiene ningún motivo para no desear la victoria de Atalanta frente a los demás competidores. Como explicaba Shackleton Bailey $(1981,335)$ en el artículo en que conjeturó insidiasque $^{54}$, el sentido de la frase es el siguiente: Hipómenes teme que

${ }^{54} \mathrm{La}$ inmensa mayoría de los códices ofrece invidiamque, que estimo preferible. Véase, por 
algún otro pretendiente use los estratagemas que él mismo usará para ganar a la hija de Esqueneo.

Sorprende que en 674 Fratantuono comente que el último tramo de la carrera era un llano, mientras que el resto hacía pendiente, y que especule sobre las habilidades de los dos contendientes en cada uno de los tramos. No hay absolutamente nada en el texto que sugiera esta topografía del terreno, como tampoco lo hay en otras carreras famosas como las de Verg. Aen. 5.286361 o Hom. Il. 23.740-97, o en otras versiones de la historia (Hes. Frg. 72-6 Merkelbach-West; Hyg. fab. 185; Ps. Apollod. 3.9.2). Más bien, como señala Reed $(2013,289)$, parece que Ovidio tiene en mente un típico estadio. En cualquier caso, no deja de ser un detalle completamente secundario para la historia narrada.

En 647, Fratantuono afirma "The tree has a shining gleam because its fruit”, pero me parece que todo el árbol es de oro: cf. 648 fulvo ramis crepitantibus auro.

También el ámbito de la sintaxis se advierten algunas interpretaciones que me parecen cuestionables.

A propósito de 583 currat, Fratantuono comenta: "present subjunctive in a clause of fear (584 timet)”. Más allá de que esto no debería ser comentable, como ya he dicho, el problema es que la frase reza así: ne quis iuvenum currat velocius optat/ insidiasque timet. Por lo tanto, ne ... currat depende de optat y ne debe traducirse negando el verbo regido.

En el periodo hipotético de los vv. 633-5 (si essem ... negarent, unus eras cum quo ... vellem), insiste por tres veces en el valor del imperfecto de subjuntivo y trata vellem como si fuese el verbo principal de la apódosis, cuando en realidad se encuentra en una oración de relativo. Lo interesante del periodo es que se emplea un imperfecto de indicativo como un irreal de presente, como bien señalaron Anderson $(1972,527)$ y Bömer $(1980,209)$.

En 380 (causam te intellige mortis) Fratantuono interpreta que te está "in apposition to causam ... mortis". Pero probablemente, sería preferible sobreentender una construcción de infinitivo con esse. Por otro lado, quizá se debería haber señalado que causam te es la lectura de unos pocos códices recentiores, inferior, en mi opinión, a la variante mayoritaria causamque, que estimo más poética. Probablemente, la variante causam te se debe a la intervención de un glosador, como ya observaron Bach ${ }^{55}$ y Loers ${ }^{56}$.

En 485 superstes no es una aposición, sino un predicativo del sujeto, como lo es también 486 mortua.

ejemplo, Bömer $(1980,196)$ y Reed $(2013,281)$, que proporcionan buenos argumentos a favor de la lección transmitida.

${ }^{55}$ P. Ovidii Nasonis Metamorphoseon libri XV. Mit kritischen und erläuternden Anmerkungen von E. C. Chr. Bach. Zweiter Band VIII-XV, Hannover, 1836, 164. 370.

${ }^{56}$ P. Ovidii Nasonis Metamorphoseon libri XV. Recensuit ... Vitus Loers, Lipsiae, 1843, 
En 567-8 (territa sorte dei per opacas innuba silvas/ vivit) Fratantuono afirma que territa está "in coordination" con 568 vivit. Un poco más abajo, en el comentario a 570 victa, asegura que "as at 567 territa, the auxiliary verb is ommitted". No tengo nada que objetar cuanto al comentario a 570 , pero en 567 territa me parece un participio en función predicativa del sujeto de vivit.

Me parece preferible entender $347 t u$ como simple nominativo, más que como vocativo. Asimismo, quizá se podría haber añadido un comentario sobre la partícula interrogativa -ne, que los lectores noveles podrían no conocer.

En 674 (inque latus campi, quo tardius illa rediret), Fratantuono traduce quo por "where" (en todo caso, sería mejor "whence", como Goold 1984,113 ), pero seguramente hay que entender la frase como final (cf. OLD 1968, 1564 s. v. quo 3b).

En 677 sublato ... malo, Fratantuono comenta "Ablative after sub-", lo que, a mi entender, es totalmente incongruente. Además, quizá es preferible interpretar el sintagma como un dativo objeto indirecto de adieci.

Por último, en 491 Fratantuono dice que firmamina no es un hapax, como, según él, afirmaba Bömer. Pero Bömer $(1980,163)$ en realiad niega que lo sea, desmintiendo así a Haupt-Ehwald ${ }^{57}$.

Señalo también que en 467-8 Fratantuono remite a 5.333 para el uso de forsitan con indicativo, siguiendo a Bömer $(1980,158)$. Pero Tarrant (2004, 137) editó forsitan otia non sint, rechazando la variante sunt.

\section{Simbolismos fonéticos y sintácticos}

Uno de los aspectos más recurrentes y entusiastas del trabajo de Fratantuono, pero también uno de los más censurables, es la tentativa de atribuir un sentido a diversos elementos sonoros (sinalefas, elisiones, aliteraciones, ritmo, etc.) o sintácticos del texto. Fratantuono, pues, participa de la fantasía según la cual el poeta hace uso de una aliteración o elige un ritmo u otro con el objetivo de describir o imitar lo que desea expresar. Sin perjuicio de que puedan existir en la literatura latina unos escasos ejemplos en que esa voluntad sea manifiesta, por lo general, se trata de un enfoque sesgado, resbaladizo y moldeable a placer. Propongo que analicemos algunos de los casos que Fratantuono plantea.

En el verso 706, Fratantuono asegura que la aliteración pugna pectora praebet verbaliza "the imagined sound of the imagined beast when confronted”. Un poco más abajo, en el v. 723, afirma que la aliteración de percussit pectora palmis describe "the godess' physical self-abuse". Parece evidente, pues, que Fratantuono atribuye a la aliteración de $p$ - la facultad de

${ }^{57}$ Die Metamorphosen des P. Ovidius Naso. Zweiter Band. Buch VIII-XV: im Anschluss an Moriz Haupts Bearbeitung der Bücher I-VII erklärt von Otto Korn in dritter Auflage neu bearbeitet von R. Ehwald, Berlin, 1898, 125. 
representar golpes o actos agresivos y violentos. Sin embargo, ese hipotético significado de la aliteración de $p$ - se desvanece cuando examinamos más ejemplos. En el libro décimo detecto los siguientes: 101 (piceae pomoque), 102 (praemia, palmae), 444 (praesagaque pectora), 469 (plena patris), 627 (pretium patietur), 638 (ejemplo citado y discutido más abajo), 654 (posse putes) o incluso 502 (potest parientis voce vocari). Sugiero también, entre muchísimos otros ejemplos posibles, la comparación con 2.99 poenam, Phaëthon, pro munere poscis; 2.126-7 parere parentis, / parce, puer; 2.179 penitus penitusque patentis. Si tuviéramos que atribuir un sentido a todas estas otras aliteraciones, debería ser radicalmente distinto al que se le otorga en 706 y 723 y difícilmente encontraríamos dos sentidos iguales. Se hace evidente, pues, que el procedimiento para dotar de "significado" a las aliteraciones es errático y sumamente subjetivo. Por lo demás, el "sentido" no depende de la aliteración, sino del contexto en que esa aparece.

Por otro lado, es una lástima que Fratantuono no hiciera mención de otra característica estilística notable del verso 706, quizá más relevante: la disposición completamente quiástica de sus elementos. En cuanto a 723, habría bastado señalar, como Bömer (1980, 230), que este tipo de aliteración es recurrente en los lamentos.

En el v. 638, Fratantuono apostilla: "The alliterative force of populusque paterque, together with the use of enclitic connectives, helps to underscore the insistence of the girl's father and the crowd". Por la misma regla, uno se podría preguntar legítimamente: ¿qué enfatizaría exactamente la repetición de las enclíticas en una juntura similar como 401 genetrixque paterque, sobre la que Fratantuono no dice nada? ¿Qué significado tendrían las "strinking alliteration[s]" de 432 spicea serta suarum o de 621-2 nubere nulla / nolet?

Por parte de Fratantuono, habría sido más instructivo y ajustado a la realidad indicar que el uso de la doble enclítica es un rasgo propio de la alta poesía (se trata, de hecho, de un helenismo introducido por Ennio en la poesía latina ${ }^{58}$ ) y que populusque paterque es el equivalente poético de $S P Q$ (Gierig 1807, 121; Luck 2005, 264; 2009, 107). Asimismo, se podría haber sugerido la comparación con la juntura parecida del v. 401, ya citada.

El caso anterior es llevado al extremo en el comentario a 656. Fratantuono asegura que la aliteración adiciunt animos refleja la acción de la multitud aplaudiendo a los contendientes, mientras que la repetición de la enclítica clamorque favorque evoca la repetición del grito alentador del público.

Otro caso muy significativo es el v. 736. Fratantuono cree que el ritmo espondaico es deliberado, ya que el poeta desea que la audiencia se detenga sobre la escena y perciba los vínculos intertextuales con el libro 5. Nada más

${ }^{58}$ Véase Norden a Verg. Aen. 6.336 (P. Vergilius Maro. Aeneis Buch VI. Erklärt von Eduard Norden. Vierte Auflage. Stuttgart, 1957, 228) y Wills 1996, 372-6. 
lejos de la realidad ${ }^{59}$. Ovidio organizó este verso de modo que estableciera un fuerte contraste rítmico con el verso siguiente, que es holodactílico (Anderson 1972, 535). Fratantuono completa su comentario estilístico al v. 736 señalando que lento ... sub cortice está aquí envuelto por el elemento que en la natura se ocupa de envolver (qualem ... granum). Pero el efecto no existe, puesto que qualem se refiere a flos del verso anterior y no puede concertar con granum.

En cualquier caso, es interesante y revelador comparar la interpretación que hace Fratantuono de este v. 736 con su tratamiento del v. 678, donde se habla del retraso y la lentitud de Atalanta al haberse desviado para recoger la manzana de oro a la que se ha añadido peso suplementario. No me cabe duda de que, si el verso fuera también espondaico, Fratantuono habría dicho que el ritmo del verso era reflejo de estos particulares. Sin embargo, Ovidio empleó un verso holodactílico (que, según los adeptos a los simbolismos fonéticos, podría expresar movimiento, ligereza o excitación: cf. Bömer 1980, 436). A falta de un ritmo conveniente y "adecuado" al tema, Fratantuono halló otro elemento prosódico capaz de sintetizar la materia del verso; según él, la elisión de impediique oneris "reflects the scenario, as the action of the goddess in weighing down the apple slows down the swift girl" (sic).

Mi estupefacción también es completa cuando en 110 Fratantuono asegura que el encabalgamiento representa la sombra que proyectan los cuernos del ciervo de Ciparís, o cuando en 700-1 (in pectora totum/ pondus abit) asegura que el encabalgamiento condensa "the heaviness of the weight". Me parece igualmente descabellado su comentario al v. 653, donde afirma que los verbos en singular (emicat y libat) junto a uterque ayudan a crear la ilusión de que los dos contendientes (Hipómenes y Atalanta) se funden en uno. Francamente, me queda la duda sobre si en el verso siguiente, donde Ovidio se refiere a ellos mediante el pronombre illos, los dos contrincantes siguen fusionados o no.

Creo que estos ejemplos muestran bien hasta qué punto la atribución de "significado" o sentido a los elementos sonoros y sintácticos del verso como reflejo o imitación de su sentido es un procedimiento aleatorio que depende de la casualidad y de la desatada subjetividad del comentarista. En todos estos ejemplos, como en los otros muchos casos en que Fratantuono detecta simbolismos fonéticos o sintácticos (vv. 1, 3, 23, 27, 65, 69, 72, 121, 125, $177,195,204,250,286,322,340,343,350,362,374,402,412,460,560$, $566,587,601,653,657,663,665,669,670,673,680,714,720)$, lo justo habría sido limitarse a señalar los recursos empleados por el poeta, esclarecer

${ }^{59}$ Bömer $(1980,339)$ a 11.394 clasifica este verso entre los "sine causa ponderosi”, ya que no se adecua a las "significaciones" atribuidas normalmente a los versos espondaicos. 
su valor estilístico y su contribución en la creación del lenguaje poético ${ }^{60}$, sin asignarles un sentido de forma arbitraria y engañosa.

A la vista de todo ello y a pesar de algunas buenas ideas y reflexiones, creo que se puede afirmar que el libro de Fratantuono es un comentario escolar poco profundizado, con signos de una redacción rápida y abrupta, y lleno de repeticiones innecesarias. Además, con demasiada frecuencia se refugia en la glosa fácil o trivial y en aspectos secundarios del texto y de la obra. De esta forma, no es muy difícil ufanarse (p. vi) de que las notas sean más extensas y detalladas que las de sus predecesores en lengua inglesa ${ }^{61}$. Otro asunto es que las notas sean más detalladas en cantidad o en calidad.

Asimismo, como hemos visto, el texto está lastrado por errores materiales, inexactitudes, criterios filológicos borrosos y por concepciones disparatadas sobre el lenguaje literario. Dudo, pues, que nada de ello vaya a resultar particularmente útil a los estudiantes en su formación e instrucción $\mathrm{y}$, sin duda, no creo que vaya a resultar provechoso a los especialistas. En mi opinión, los estudiantes deberán seguir recurriendo al óptimo comentario escolar de William S. Anderson (1972) y los especialistas al monumental e imprescindible comentario de Franz Bömer (1980), así como al valioso trabajo de Reed (2013).

\section{REFERENCIAS BiBLIOGRÁfICAS}

Anderson 1972. W. S. Anderson, Ovid's Metamorphoses, Books 6-10, Norman.

Anderson 1991. P. Ovidii Nasonis Metamorphoses. Edidit William S. Anderson, Stutgardiae et Lipsiae.

Bömer 1980. P. Ovidius Naso, Metamorphosen. Kommentar von Franz Bömer. Buch X-XI, Heildelberg.

Bömer 1986. P. Ovidius Naso, Metamorphosen. Kommentar von Franz Bömer. Buch XIV-XV, Heidelberg.

Burman 1727. Publii Ovidii Nasonis Metamorphoseos libri xv cum integris ... notis, quibus et suas adnotationes adiecit Petrus Burmannus. Tom. II, Amstelodami.

Gierig 1807. P. Ovidii Metamorphoses recensuit varietate lectionis notisque instruxit Gottlieb Erdmann Gierig. Editio altera ad singulos prope versus vel emendatior vel auctior. Tomus posterior, Lipsiae.

${ }^{60}$ Los elementos que configuran la forma del texto, como las aliteraciones, el ritmo, etc., tienen como objetivo la cancelación de la función referencial; secundariamente, se contagian del sentido, estimulan nuestra imaginación y juegan un papel importante en otorgar verosimilitud al relato. Véase S. Oliva, La rehumanización del arte (ética y estética en la literatura y las artes), Salamanca, 2015.

${ }^{61}$ A saber: Anderson (1972) y Hill (Ovid, Metamorphoses IX-XII. Edited with an introduction, translation and notes by D. E. Hill, Warminster, 1999). 
Goold 1984. Ovid, III Metamorphoses, II Books IX-XV. With and English Translation by Frank Justus Miller, revised by G. P. Goold, Third Edition, London.

Heinsius 1659. P. Ovidii Nasonis Operum tomus II qui Metamorphoses complectitur. Nicolaus Heinsius D. F. locis infinitis ex fide scriptorum exemplarium castigavit et observationes adiecit, Amstelaedami.

Housman 1890. A. E. Housman, "Emendations in Ovid's Metamorphoses", TCPh 3, 1890, 140-153.

Liberman 2004. G. Liberman, "Observations sur le texte des Métamorphoses d'Ovide", $R P h$ 78, 2004, 57-90.

Luck 2005. G. Luck, "Reseña a R. J. Tarrant, P. Ovidi Nasonis Metamorphoses ... Oxford University Press, 2004”, ExClass 9, 2005, 249-71.

Luck 2008. G. Luck, "Notes on the Text of Ovid's Metamorphoses”, ExClass 12, 2008, 49-67.

Luck 2009. G. Luck, "More missing letters in Ovid's Metamorphoses", $M H$ 66, 2009, 88-119.

Merkel 1878. P. Ovidius Naso ex iterata R. Merkelii recognitione. Vol. II Metamorphoses cum emendationis summario, Lipsiae.

Reed 2013. Ovidio. Metamorphosi, volume V, libri X-XII, a cura di Joseph D. Reed, trad. di G. Chiarini, Fondazione Lorenzo Valla.

Shackleton Bailey 1981. D. R. Shakleton Bailey, "Notes on Ovid's Metamorphoses”, Phoenix 35, 1981, 332-337.

Tarrant 2004. P. Ovidi Nasonis Metamorphoses. Recognovit brevique adnotatione critica instruxit R. J. Tarrant, Oxonii.

Wills 1996. J. Wills, Repetition in Latin Poetry. Figures of Allusion, Oxford.

Pere Fàbregas Salis Universidad de Barcelona fabregasalis@gmail.com 